\title{
Winner of the Classification Society Distinguished Dissertation Award 2008
}

The Award honors the best $\mathrm{PhD}$ (or approximately equivalent doctoral) dissertation nominated by an annual deadline. The theme is clustering, classification, related areas of data analysis, encompassing both associated theory and/or applications.

In 2007-2008, the evaluation committee included: Fionn Murtagh (chair, Science Foundation Ireland, and Department of Computer Science, Royal Holloway, University of London), Samantha Prins (Department of Mathematics \& Statistics, James Madison University), Douglas Steinley (Department of Psychological Sciences, University of Missouri-Columbia) and Willem Heiser (Department of Psychology, Leiden University).

In 2008 the Award totals US\$ 500 in book vouchers from Chapman and Hall/CRC. The winner is invited to make a presentation in a special plenary session at the Classification Society Annual Meeting with up to $\$ 500$ of the Award winner's travel expenses to the Annual Meeting covered by the Classification Society.

There were 10 excellent nominations, which are listed at: http://www.classification-society.org/csna/csna.html

The first, 2008 Distinguished Dissertation Award winner is:

\section{Dr Anita Van der Kooij}

for her dissertation

\section{"Prediction Accuracy and Stability of Regression with Optimal Scaling Transformations"}

defended at Leiden University under supervision of Professor Jacqueline Meulman, in June 2007. 